\title{
The Comaneci Device for Entering an Acute-Angled Small Feeder during Cerebral Arteriovenous Malformation Emboli- zation: A Novel Technique to Support Microcatheterization
}

\author{
Lars Wessels, $\mathrm{MD}^{1,2}$, Joost de Vries, $\mathrm{MD}, \mathrm{PhD}^{1}$, Hieronymus D. Boogaarts, $\mathrm{MD}, \mathrm{PhD}^{1}$ \\ ${ }^{1}$ Department of Neurosurgery, Radboud University Medical Center, Nijmegen, The Netherlands \\ ${ }^{2}$ Department of Neurosurgery and Center for Stroke Research Berlin (CSB) Charité-Universitätsmedizin Berlin, Berlin, Germany
}

In this report, we describe the use of the Comaneci device to support microcatheterization in a small branch arising from a parent artery during embolization. In 2 cases, arteriovenous malformations presented with intracranial hemorrhage. A microcatheter was navigated into a small feeder while the Comaneci device was deployed just distal to the feeder with an acute angle from the parent artery. Our technical note represents an alternative option of catheterization in cases with difficult access to small feeders originating from higher flow arteries at a sharp angle while maintaining continuous flow in the parent artery.

Key Words: Comaneci; Arteriovenous malformations; Catheterization

\section{INTRODUCTION}

Microcatherization in arteriovenous malformation (AVM) embolization can be challenging, especially when it is necessary to enter a very small branch with an acute angle from a high-flow parent artery. Normally, this involves changing microwires or microcatheters to overcome this problem, but this still often is a limiting factor in accessing AVMs for embolization. The Comaneci device (Rapid Medical, Yokneam, Israel) is the first-ever adjustable, fully-visible remodeling device. It is intended to provide temporary assistance for coil embolization of intracranial aneurysms. It maintains the advantages of existing adjuvant devices without the risk of parent vessel occlusion during the coiling procedure or the need for long-term antiplatelet medication in case of permanent stenting. ${ }^{2-6}$

The device is CE marked and approved in the USA and Canada. The distal end of the device consists of a $7 \mathrm{~mm}$ flexible tip, allowing for gentle and safe navigation. It has a controllable compliant radiopaque mesh composed of 12 nitinol wires mounted on a $182 \mathrm{~cm}$ core wire. The standard version can be expanded from 1.5 to $4.5 \mathrm{~mm}$ and has a length of 32 $\mathrm{mm}$, which shortens to $12 \mathrm{~mm}$ when deployed in a vessel of $4.0 \mathrm{~mm}$ in diameter. The middle version (Coma-

\section{Correspondence to:}

Hieronymus D. Boogaarts, MD, PhD Department of Neurosurgery, Radboud University Medical Center, Geert Grooteplein Zuid 10, Nijmeegen, The Netherlands Tel: +31-024-361-66-04 Fax: +31-024-361-66-00 E-mail: Jeroen.Boogaarts@radboudumc.nl

Received: March 31, 2020 Revised: May 16, 2020 Accepted: May 18, 2020

Copyright $\odot 2020$ Korean Society of Interventional Neuroradiology This is an Open Access article distributed under the terms of the Creative Commons Attribution Non-Commercial License (http://creativecommons.org/licenses/by-nc/4.0) which permits unrestricted non-commercial use, distribution, and reproduction in any medium, provided the original work is properly cited.

pISSN 2093-9043 eISSN 2233-6273 
neci Petit) can be expanded from 1.5 to $3.5 \mathrm{~mm}$, and measures $24 \mathrm{~mm}$ before deployment and contracts to $21 \mathrm{~mm}$ when fully deployed in a vessel of $3.0 \mathrm{~mm}$ in diameter. Both versions are compatible with a microcatheter of 0.021". The smallest version (Comaneci 17) can be expanded from 0.5 to $3 \mathrm{~mm}$ and is delivered via a 0.017-inch microcatheter. It measures $22 \mathrm{~mm}$ before deployment and contracts to $16 \mathrm{~mm}$ when fully opened in a vessel of $3.0 \mathrm{~mm}$ in diameter.

We present an alternative option with the Comaneci device to support navigation of the microcatheter into a very small branch of an AVM. This technique can provide useful options in a situation involving difficult access of a microcathter.

\section{CASE REPORT}

\section{Case 1}

A 26-year-old male patient presented with sudden onset of an acute headache and right-sided hemiparesis. The initial computed tomography (CT) showed an intracerebral hemorrhage in the left temporoparietal area. Digital subtraction angiography (DSA) revealed a small left parietal AVM as a Spetzler \& Martin grade I (Fig. 1A-C). Following interdisciplinary discussion between neuroradiology, neurosurgical, and neurological teams, endovascular treatment was determined to be the best treatment option to prevent rebleeding. Four
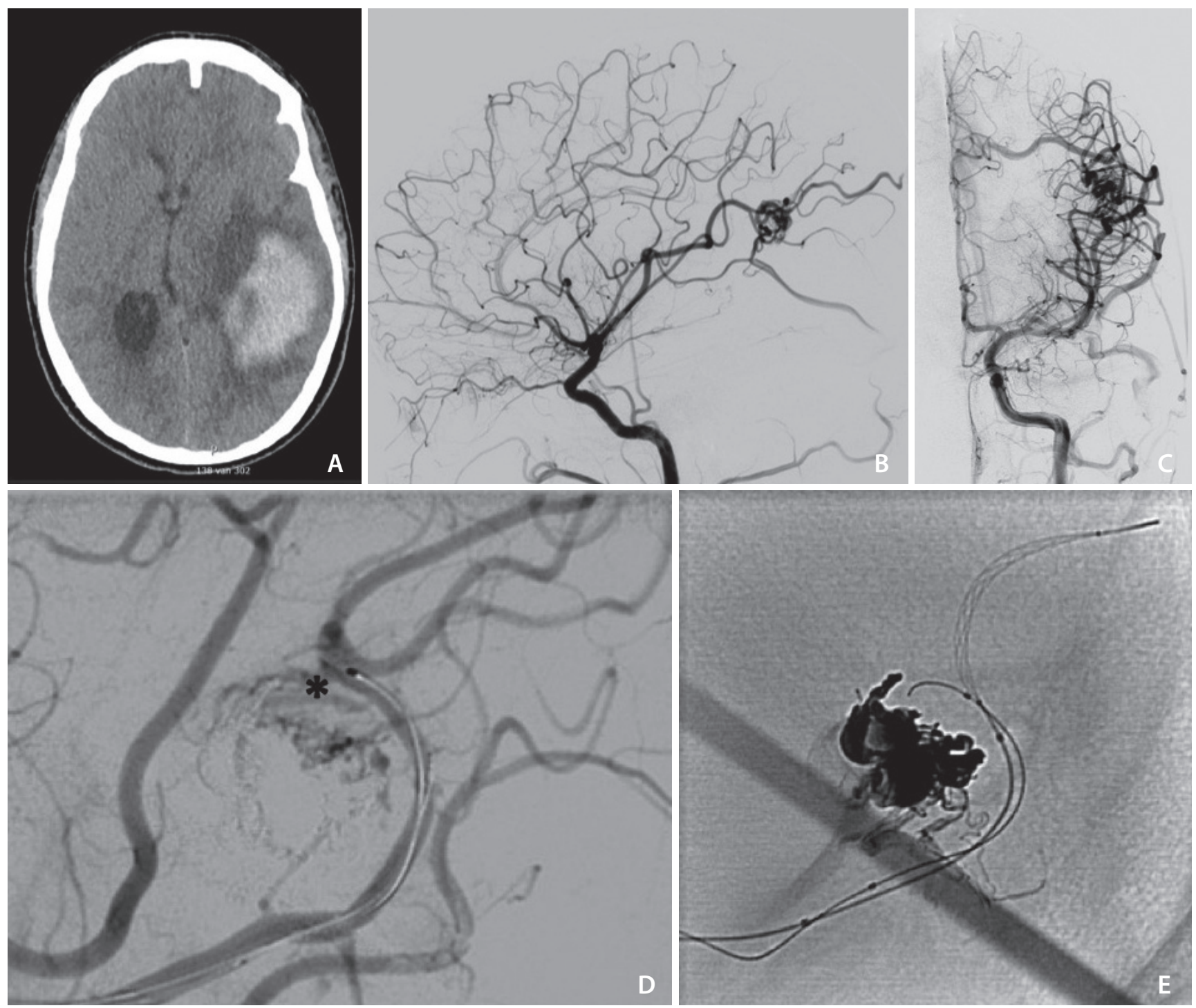

Fig. 1. (A-C) Preoperative native computed tomography and digital subtraction angiography (DSA) (lateral and anterior posterior view) of the presented case before treatment. (D, E) DSA with partial embolization, microcatheter before the branch to enter (asterisk), and Comaneci inflated and microwire in the target branch. 
weeks following the ictus, the procedure was performed without complication. The patient had a prolonged clinical stay and was discharged to rehabilitation with right-sided hemiparesis.

An $8 f$ Infinity long sheet catheter (Stryker, Kalamazoo, MI, USA) was used for access in combination with a standard guidewire (Radifocus, Terumo, Belgium). Heparin 3,500 units was administered. A CAT 5 Distal Access Catheter (Stryker) in combination with an Apollo 2.7F microcatheter (Codman, Fremont, CA, USA) and an Asahi Chikai 008 microwire (Asahi Intecc, Nagoya, Japan) was used to navigate to the AVM. Partial embolization was performed through a small branch using Onyx (Medtronic, Dublin, Irland). The control DSA showed residual filling through a small branch with an acute curve of the navigating course (Fig. 2A). The first attempt using an Apollo 2.7F was not able to navigate this branch due to the difficult angle affecting the vulnerable support of the microcatheter. As a second option, a Comaneci 17 device (Fig. 2B) was deployed to the distal part of the branching orifice from a parent artery. Once the device was in place, it was possible to navigate Asahi Chikai 008 microwire and the microcatheter to the small branch, and successful embolization was achieved.
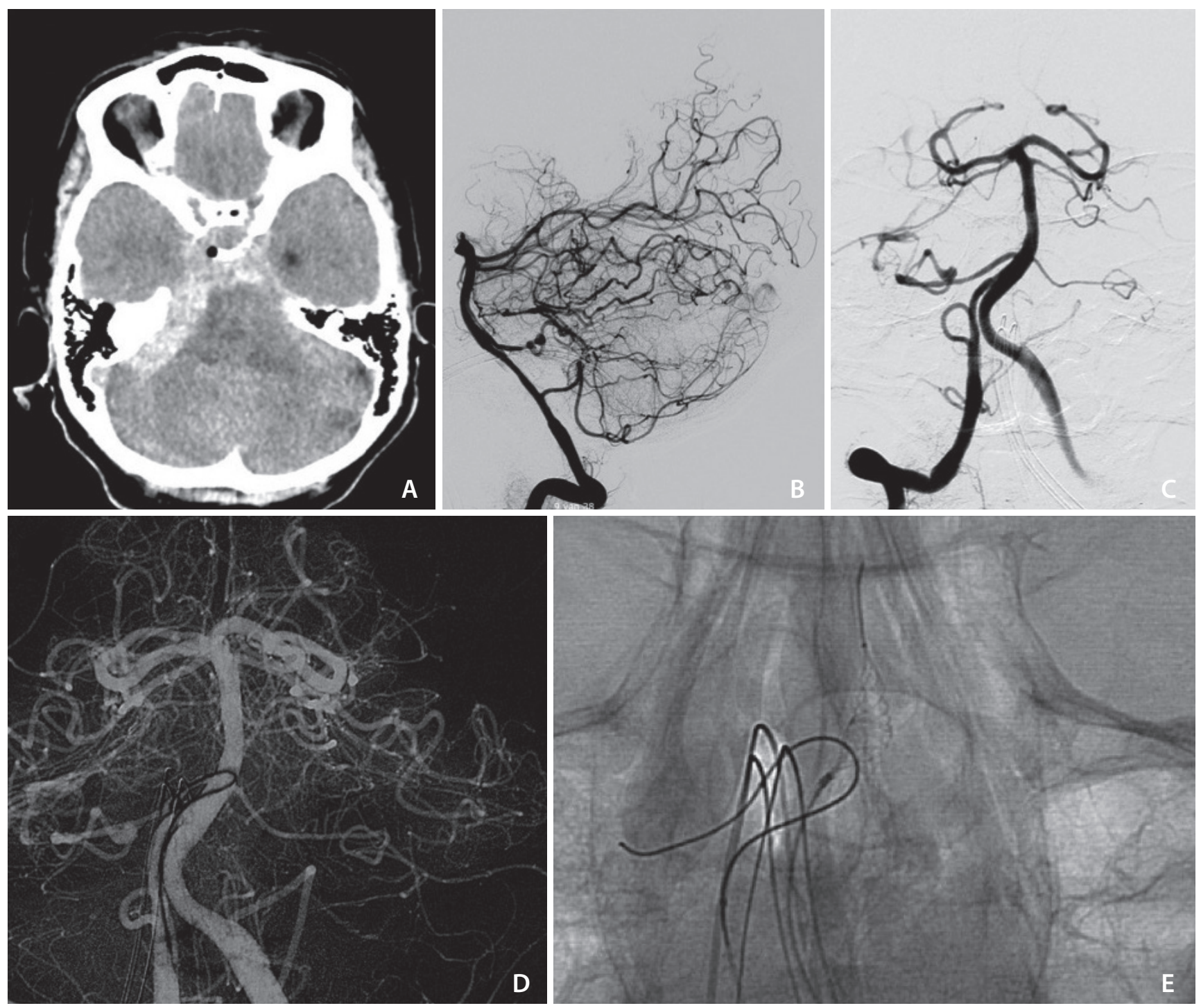

Fig. 2. (A-C) Preoperative native computed tomography and digital subtraction angiography (DSA) (lateral and anterior posterior view) of the presented case before treatment. (D) DSA microwire in the origin AICA; further advancement is not possible due to a leek of support in the parent artery. (E) Comaneci inflated and microwire in the target branch. 


\section{Case 2}

The 71-year-old female patient presented with sudden onset of an acute headache, dizziness, and vomiting. The initial CT showed a subarachnoid hemorrhage with maximal expansion in the right posterior fossa. The DSA revealed a small AVM as a Spetzler \& Martin grade I with arterial feeders from the right anterior inferior cerebellar artery (AICA) and a flow-related aneurysm. The endovascular embolization was performed 1 day after the ictus to prevent re-bleeding from the flow-related aneurysm. A 5F Envoy catheter (Codman) was used for access of the right vertebral artery in combination with a standard guidewire. The first attempt to enter the AICA using an Excelsior SL-10 microcatheter (Stryker) in combination with a Synchro guidewire (Stryker) failed. It was possible to enter the origin of the AICA, but due to the large lumen of the basilar artery in combination with the sharp angle of the AICA, the microwire did not have enough support and dislocated every time the microcatheter was advanced. Therefore a Prowler select plus Catheter (Codman) in combination with a Synchro guidewire was additionally inserted via the left vertebral artery. Using the Prowler select plus Catheter, a Comaneci device was advanced and deployed distal to the AICA origin. With the support of the Comaneci, the SL-10 could be advanced into the AICA and the Vessel was occluded using Nano coils (Stryker). Post-embolization angiography showed no residual filling of the aneurysm, but still showed a slight filling of the AVM .

\section{DISCUSSION}

Endovascular embolization of AVMs can be a challenging procedure, especially in patients presenting with hemorrhage, in which complete embolization should be achieved? One of the limitations of treatment, especially of small AVMs, is difficult accessibility of feeding arteries due to the complex anatomy of cerebral vessels. Good accessibility can be obtained using the Comaneci, which provides a compliant remodeling mesh, comparable to a compliant balloon, without the drawback of flow disturbance within the parent artery during expansion of the device. Once the Comaneci stent was deployed to the distal part from the orifice of feeder, no further deflation and inflation maneuver was required, and this could introduce a barrier to prevent distal moving of the microcatheter toward parent artery. In this regard, blocking alternative routes as a way to enter small branches with a sharp angle can be considered with a highly compliant balloon, but this is not applicable in very small branches due to the size of the balloons and the blockage of the blood flow in the parent artery.

To get an effective blocking and supporting effect for the microcatheter, it is of great relevance to have a maximal safe expansion of the device and continuous flow in the parent artery. The use of the Comaneci device requires a second microcatheter, which can result in an increased periprocedural risk. This potential risk is, from our point of view, outweighed by its benefits, and the use is recommended when other less invasive access techniques fail. Additional technical drawbacks of the Comaneci are the need for a comparatively large microcatheter and the somewhat jerky reaction of the device to the manipulation of the slider. Despite some technical limitations, the use of Comaneci can be considered as an alternative option for difficult access, not only for AVM treatment but also for aneurysms or dural arteriovenous fistulas.

\section{CONCLUSION}

The comaneci device can be used to get distal support while entering small feeders with sharp angles in AVM embolization.

\section{Fund}

None.

\section{Conflicts of Interest}

The authors have no conflicts to disclose.

\section{Author Contribution}

Concept and design: HDB. Analysis and interpretation: LW, HDB, and JdV. Writing the article: LW and HDB. Data collection: LW. Critical revision of the article: JdV and HDB. Final approval of the article: HDB and JdV. Obtained funding: none. Overall responsibility: $\mathrm{HDB}$.

\section{ORCID}

Lars Wessels: https://orcid.org/0000-0001-8056-9659

Joost de Vries: https://orcid.org/0000-0002-9953-5069

Hieronymus D. Boogarts: https://orcid.org/0000-0001-5855-2447 


\section{REFERENCES}

1. Gupta R, Kolodgie FD, Virmani R, Eckhouse R. Comaneci neck bridging device for the treatment of cerebral aneurysms. J Neurointerv Surg 2016;8:181-185

2. Maingard J, Kok HK, Phelan E, Logan C, Ranatunga D, Brooks DM, et al. Endovascular treatment of wide-necked visceral artery aneurysms using the neurovascular comaneci neck-bridging device: a technical report. Cardiovasc Intervent Radiol 2017:40:1784-1791

3. Sirakov S, Sirakov A, Hristov H, Minkin K, Penkov M, Karakostov V. Early experience with a temporary bridging device (Comaneci) in the endovascular treatment of ruptured wide neck aneurysms. J Neurointerv Surg 2018;10:978-982

4. Sirakov SS, Sirakov A, Hristov H, Raychev R. Coiling of ruptured, wide-necked basilar tip aneurysm using double Comaneci technique. BMJ Case Rep 2018;2018:bcr2017222703

5. Lawson AL, Chandran A, Puthuran M, Goddard T, Nahser H, Patankar T. Initial experience of coiling cerebral aneurysms using the new Comaneci device. J Neurointerv Surg 2016;8:e32

6. Sirakov SS, Panayotova AP, Sirakov AS, Hristov H, Minkin K, Raychev R. Fenestration of the basilar artery associated with aneurysm treated by the support of a temporary bridging device-comaneci: a case report. World Neurosurg 2018;119:306310

7. Wu EM, El Ahmadieh TY, McDougall CM, Aoun SG, Mehta N, Neeley OJ, et al. Embolization of brain arteriovenous malformations with intent to cure: a systematic review. J Neurosurg 2019;132:388-399 